\title{
Modifiable risk factors associated with prediabetes in men and women: a cross-sectional analysis of the cohort study in primary health care on the evolution of patients with prediabetes (PREDAPS-Study)
}

Alicia Díaz-Redondo ${ }^{1}$, Carolina Giráldez-García ${ }^{2 *}$, Lourdes Carrillo³, Rosario Serrano ${ }^{4}$, Francisco Javier García-Soidán ${ }^{5}$, Sara Artola ${ }^{6}$, Josep Franch ${ }^{7}$, Javier Díez ${ }^{8}$, Patxi Ezkurra ${ }^{9}$, José Manuel Millaruelo ${ }^{10}$, Mateu Seguí ${ }^{11}$, Javier Sangrós ${ }^{10}$, Juan Martínez-Candela ${ }^{12}$, Pedro Muñoz ${ }^{13}$, Albert Goday ${ }^{14}$ and Enrique Regidor²,15

\begin{abstract}
Background: Prediabetes is a high-risk state for diabetes development, but little is known about the factors associated with this state. The aim of the study was to identify modifiable risk factors associated with the presence of prediabetes in men and women.

Methods: Cohort Study in Primary Health Care on the Evolution of Patients with Prediabetes (PREDAPS-Study) is a prospective study on a cohort of 1184 subjects with prediabetes and another cohort of 838 subjects without glucose metabolism disorders. It is being conducted by 125 general practitioners in Spain. Data for this analysis were collected during the baseline stage in 2012. The modifiable risk factors included were: smoking habit, alcohol consumption, low physical activity, inadequate diet, hypertension, dyslipidemia, and obesity. To assess independent association between each factor and prediabetes, odds ratios (ORs) were estimated using logistic regression models.
\end{abstract}

Results: Abdominal obesity, low plasma levels of high-density lipoprotein cholesterol (HDL-cholesterol), and hypertension were independently associated with the presence of prediabetes in both men and women. After adjusting for all factors, the respective ORs (95\% Confidence Intervals) were 1.98 (1.41-2.79), 1.88 (1.23-2.88) and 1.86 (1.39-2.51) for men, and 1.89 (1.36-2.62), 1.58 (1.12-2.23) and 1.44 (1.07-1.92) for women. Also, general obesity was a risk factor in both sexes but did not reach statistical significance among men, after adjusting for all factors. Risky alcohol consumption was a risk factor for prediabetes in men, OR 1.49 (1.00-2.24).

Conclusions: Obesity, low HDL-cholesterol levels, and hypertension were modifiable risk factors independently related to the presence of prediabetes in both sexes. The magnitudes of the associations were stronger for men than women. Abdominal obesity in both men and women displayed the strongest association with prediabetes. The findings suggest that there are some differences between men and women, which should be taken into account when implementing specific recommendations to prevent or delay the onset of diabetes in adult population.

Keywords: Prediabetes, Modifiable risk factors, Primary health care, Men, Women, Spain

\footnotetext{
*Correspondence: cvalle.giraldez@gmail.com

${ }^{2}$ Department of Preventive Medicine, Public Health (History of Science),

Universidad Complutense de Madrid, Madrid, Spain

Full list of author information is available at the end of the article
}

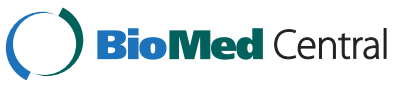

(c) 2015 Díaz-Redondo et al.; licensee BioMed Central. This is an Open Access article distributed under the terms of the Creative Commons Attribution License (http://creativecommons.org/licenses/by/4.0), which permits unrestricted use, distribution, and reproduction in any medium, provided the original work is properly credited. The Creative Commons Public Domain Dedication waiver (http://creativecommons.org/publicdomain/zero/1.0/) applies to the data made available in this article, unless otherwise stated. 


\section{Background}

Type 2 diabetes mellitus is a major public health problem, in Europe is estimated that 56.3 million -8.5\%- of adult population has diabetes and the prevalence is raising globally [1,2]. Additionally, there are some reasons that exacerbate the problem: the impact of diabetes on morbidity and mortality is well known $[1,3,4]$; the diagnosis is usually delayed around four to seven years after disease onset largely due to absence of symptoms during the early years of type 2 diabetes [5]; and, 10-20\% of persons with type 2 diabetes are found to have developed cardiovascular complications by the date of diagnosis, as a result of the high cardiovascular-disease risk entailed by type 2 diabetes per se and the elevated prevalence of cardiovascular risk factors among these patients [6]. Indeed, this is why the promotion of healthy lifestyles and an early diagnosis constitutes a key strategic line of approach to this health problem.

An appreciable percentage of the population has been observed in the so-called "prediabetic" states. In Spain, the prevalence estimated is above $12 \%$ [7]. A subject with prediabetes is defined as any person having blood glucose concentrations that are higher than normal but not of a magnitude which would correspond to a diagnosis of type 2 diabetes [8]. Individuals with prediabetes have an increase high risk of developing type 2 diabetes and associated complications, and most type 2 diabetes patients have likely been in a state of hyperglycemia for several years prior to diagnosis [9]. Prediabetes is also associated with a higher risk of major cardiovascular diseases appearing [10]. On the other hand, there evidence that changes in lifestyle can reduce or delay the appearance of diabetes in prediabetic individuals [11]. Hence, it is important to identify individuals with a higher probability of presenting some glucose metabolism disorder and know the related risk factors.

Some authors assign the same risk factors that have been identified in studies based on type 2 diabetes patients to subjects with prediabetic states [12,13]. Also, it has been suggested that some lifestyle-related risk factors and other component factors of the metabolic syndrome, implicated in the progression of the prediabetic stage to type 2 diabetes, might also contribute to the appearance of prediabetes $[13,14]$. However, few studies about this issue have been based on prediabetic individuals, and most of these have focused only on metabolic factors $[15,16]$. Moreover, in the studies that have been undertaken, the authors have tended to analyze the independent effect of these factors, adjusting for sex, thereby rendering it impossible to ascertain whether the factors analyzed display a similar relationship with prediabetes in both sexes. This is why this study aims to identify the modifiable risk factors associated with prediabetes in both men and women.

\section{Methods}

\section{Study design and subjects}

The participants were the 2022 subjects included in the Cohort Study in Primary Health Care on the Evolution of Patients with Prediabetes (Evolución de pacientes con prediabetes en Atención Primaria de Salud - PREDAPS). The background and methodology of this study have been previously published [17]; basically, it consisted of a follow-up study of a cohort of 1184 subjects with prediabetes and another cohort of 838 subjects without glucose metabolism disorders. Baseline data were collected in 2012, in the context of routine clinical practice, by 125 general practitioners distributed across Spain.

Patients who consecutively sought medical attention for any reason and met the inclusion criteria were invited by the researchers to participate in the study. A prediabetic subject was defined as anyone who fulfilled the following criteria: fasting plasma glucose (FPG) levels between 100 and $125 \mathrm{mg} / \mathrm{dl}$, and/or a glycated hemoglobin HbA1c range from $5.7 \%(39 \mathrm{mmol} / \mathrm{mol})$ to $6.4 \%(46 \mathrm{mmol} / \mathrm{mol})$ in the preceding 6 months [8]. Patients who had no results for the previous 6 months underwent analysis to determine these values. The selection of a prediabetic patient was matched by the inclusion of another patient of the same sex and similar age $(+/-5$ years), in order to form the cohort of subjects without glucose metabolism disorders. The exclusion criteria for both cohorts of subjects were age under 30 or over 74 years, and presence of any of the following processes: diabetes, terminal disease, pregnancy, major surgery or hospital admission in the preceding three months, or any hematologic diseases that might interfere with the HbA1c value.

The study was classified by the Spanish Agency of Medicines and Medical Devices (Agencia Española de Medicamentos y Productos Sanitarios) as a Non-Interventional (Observational) Post-Authorization Study, and the protocol was approved by the Parc de Salut Mar Clinical Research Ethics Committee in Barcelona. All the patients included in the study signed the informed consent form required for their participation.

\section{Measures}

Data on modifiable lifestyle-related risk factors were collected. With respect to smoking habit, subjects were classified into individuals who had smoked at some time in their lives, individuals who currently smoke, and those who had never smoked (ever smoker, current smoker and never smoker). Based on alcohol consumption patterns [18], subjects were classified into risky drinker, lowrisk drinker and abstinent categories. Men were considered as risky drinker if they have more than 4 drinks on any single day and/or they have more than 14 drinks per week. Women were considered as risky drinker if they have more than 3 drinks on any single day and/or they have more 
than 7 drinks per week. Subjects who drink but do not exceed both above limits -any single day and per week- were classified as low-risk drinker. Subjects who do not drink any alcohol were classified as abstinent. Data were obtained on the frequency -number of times in the last two weeks- and amount -mean time in minutes for each session- of different types of physical activity, and, on the basis of the data collected, the minutes per week of physical activity performed by each participant were estimated. Subjects were classified into two categories according to if they had followed or not the World Health Organization (WHO) physical activity recommendations -accumulate at least 150 minutes per week of moderate aerobic activity or 75 minutes per week of vigorous aerobic activity, or an equivalent combination of moderate and vigorous activity- [19].

Participants were asked to describe their usual breakfast, with a wide variety of foods being included as possible replies. Subjects were allocated to two groups, those who had no or an incomplete breakfast (e.g., only coffee, milk, chocolate, cocoa or yogurt), and the rest. Based on the data collected on the frequency of consumption of fruit and vegetables, subjects were classified into the following two categories: those who ate these foods daily, and those who ate them less often. In the case of consumption of fish and legumes, subjects were classified into those who ate these foods three or more times per week, and those who ate them less frequently [20].

Data on blood pressure, height, weight, and waist circumference were obtained by physical examination. Patients were deemed to be hypertensive if their mean systolic pressure -three readings- was $\geq 140 \mathrm{mmHg}$, or their mean diastolic pressure was $\geq 90 \mathrm{mmHg}$, or if they were undergoing treatment with some type of antihypertensive medication, or if they had personal history of hypertension. General obesity was defined as a Body Mass Index (BMI) $\geq 30 \mathrm{Kg} / \mathrm{m}^{2}$, and abdominal obesity as a waist circumference $\geq 102 \mathrm{~cm}$ in men and $\geq 88 \mathrm{~cm}$ in women [21].

Finally, plasma lipid concentrations were determined, subjects were deemed to have high cholesterol if their levels were $\geq 250 \mathrm{mg} / \mathrm{dl}$, and high triglycerides if their levels were $\geq 200 \mathrm{mg} / \mathrm{dl}$; and they were deemed to have low high-density lipoprotein cholesterol (HDL-cholesterol) if their plasma levels were $<40 \mathrm{mg} / \mathrm{dl}$ in men and $<50 \mathrm{mg} /$ $\mathrm{dl}$ in women. Other variables, included in this study due to their potential confounding effect with respect to the association studied, were: age, marital status, educational level, region of residence, and family history of diabetes.

\section{Statistical analyses}

We estimated the percentage of patients who presented each of these risk factors in the cohort of subjects with prediabetes and in the cohort without glucose metabolism disorders, with a breakdown by sex. We assessed the statistical significance of the difference in percentages between the two groups using the chi-squared test. A p-value $<0.05$ were considered statistically significant. In order to evaluate the independent association, in men and in women, between risk factors and presence of prediabetes, logistic regression models were performed. First, we estimated the association between each risk factor and prediabetes using models adjusted for age, marital status, educational level, region of residence, and family history of diabetes. Second, all risk factors were introduced in the models. The estimates were expressed in odds ratios (ORs) and 95\% confidence intervals (95\% CIs). These analyses were performed using the SPSS statistical package version 19.

\section{Results}

Characteristics of subjects with prediabetes and those without glucose metabolism disorders are shown in Table 1, with a breakdown by sex. Whereas age, percentage of low educational level, and presence of family history of diabetes were higher among subjects with prediabetes, in both men and women, no statistically significant differences were found in terms of marital status or region of residence.

The frequency of risk factors in both cohorts of subjects is shown in Table 2. No significant differences in physical activity, diet, and hypercholesterolemia were found. Men and women with prediabetes registered a higher frequency of hypertension, low HDL-Cholesterol level, general obesity, and abdominal obesity than men and women without glucose metabolism disorders. Among men, the percentage of current smokers was lower and the percentage of risky drinkers was higher in the prediabetes group than in the group without glucose metabolism disorders. Women with prediabetes displayed a higher prevalence of hypertriglyceridemia than women without glucose metabolism disorders.

The ORs that reflect the association between each of the risk factors and presence of prediabetes in men and in women are shown in Tables 3 and 4, respectively. In model 1, the ORs -adjusted for age, educational level, marital status, region of residence, and family history of diabetes- showed an elevated magnitude for hypertension, low HDL-Cholesterol, general obesity, and abdominal obesity in men and women alike. In men, risky alcohol consumption and hypertrigliceridemia also yielded elevated and significant ORs. In women, incomplete or absent breakfast and hypertrigliceridemia were elevated but no significant OR.

After adjustment for all risk factors (model 2), hypertension, low HDL-Cholesterol plasma levels and abdominal obesity showed an independent association with prediabetes in men and women. Furthermore, alcohol consumption 
Table 1 Percent distribution of sociodemographic characteristics and family history of diabetes mellitus in men and women

\begin{tabular}{|c|c|c|c|c|c|c|}
\hline \multirow[t]{3}{*}{ Characteristics } & \multicolumn{3}{|c|}{ Men } & \multicolumn{3}{|c|}{ Women } \\
\hline & With prediabetes & $\begin{array}{c}\text { Without glucose } \\
\text { metabolism disorders }\end{array}$ & $\overline{p \text {-value }}$ & With prediabetes & $\begin{array}{c}\text { Without glucose } \\
\text { metabolism disorders }\end{array}$ & $\overline{p \text {-value }}$ \\
\hline & $\mathrm{N}=595$ & $N=388$ & & $N=589$ & $N=450$ & \\
\hline \multicolumn{7}{|l|}{ Age } \\
\hline 30-49 years & 16.5 & 22.4 & 0.013 & 15.1 & 25.3 & $<0.001$ \\
\hline $50-64$ years & 50.4 & 51.8 & & 49.1 & 46.4 & \\
\hline $65-74$ years & 33.1 & 25.8 & & 35.8 & 28.2 & \\
\hline \multicolumn{7}{|l|}{ Educational level $^{*}$} \\
\hline Low & 59.0 & 52.3 & 0.042 & 70.1 & 59.6 & $<0.001$ \\
\hline High & 41.0 & 47.7 & & 29.9 & 40.4 & \\
\hline \multicolumn{7}{|l|}{ Marital status } \\
\hline Without partner & 15.8 & 18.3 & 0.337 & 27.5 & 27.1 & 0.944 \\
\hline Married or with partner & 84.2 & 81.7 & & 72.5 & 72.9 & \\
\hline \multicolumn{7}{|l|}{ Region of residence $^{\dagger}$} \\
\hline North & 41.5 & 39.4 & 0.131 & 36.2 & 36.0 & 0.955 \\
\hline Centre & 30.4 & 36.3 & & 33.6 & 34.4 & \\
\hline South & 28.1 & 24.2 & & 30.2 & 29.6 & \\
\hline \multicolumn{7}{|c|}{ Family history of diabetes $^{\ddagger}$} \\
\hline Yes & 43.4 & 33.8 & 0.003 & 50.6 & 34.2 & $<0.001$ \\
\hline No & 56.6 & 66.2 & & 49.4 & 65.8 & \\
\hline
\end{tabular}

Data are showed in percentages.

"Low educational level: lower than secondary (equivalent to less than 12 years of education); high educational level: secondary or higher (equivalent to 12 years or more of education).

${ }^{\dagger}$ North: Galicia, Asturias, Cantabria, Basque Country, Navarre, La Rioja, Aragon, Catalonia; Centre: Castile- León, Madrid, Extremadura, Castile-La Mancha; South: Andalusia, Murcia, Valencia, Balearic Isles, Canary Islands.

${ }^{\ddagger}$ Family history of diabetes in father, mother, siblings or children.

showed an independent association in men, and general obesity showed an independent association in women.

\section{Discussion}

This study showed that known cardiovascular risk factors, specifically abdominal obesity, hypertension and low HDL-Cholesterol levels, are independently associated with the presence of prediabetes in women and men alike. Additionally, general obesity in women and alcohol consumption in men are risk factors for prediabetes. General obesity was also associated with prediabetes in men, although the statistical significance disappeared after adjustment for all factors. The modifiable risk factors that showed the strongest association with prediabetes was abdominal obesity. The magnitudes of the associations were stronger for men than women. Smoking, physical activity, and diet habits not showed significant relationship with prediabetes.

As other studies, obesity in our study subjects -both general and, more specifically, abdominal- was associated with the presence of prediabetes $[7,22]$. Moreover, when a wide number of risk factors had been examined simultaneously, as we have done in our study, waist circumference had showed the strongest direct effect on prediabetes [22]. Although the mechanisms are not clear, excess adipose tissue has been reported to release fatty acids, something that induces resistance to insulin in the muscle and, in turn, leads to elevation of plasma glucose levels [13]. Also, measures of abdominal obesity have been found as the strongest predictors of diabetes [23].

The association between hypertension/dyslipidemia and prediabetes has been reported previously $[7,14,24]$. In our study, hypertension displayed an important association with prediabetes, particularly among men. Hypertriglyceridemia and low HDL-Cholesterol levels were also seen to be associated with prediabetes, though only the association with low HDL-Cholesterol levels proved to be significant in both sexes. Moreover, when the rest variables had been adjusted for, the magnitude of the association between these factors and prediabetes fell substantially in both sexes, though hypertension and low HDL-Cholesterol levels remain as independent risk factors for prediabetes. This weakening, in the association between dyslipidemia and hypertension with prediabetes, is basically due to the inclusion of obesity in the model. This is supported by the strong association existing between obesity and blood 
Table 2 Percent distribution of modifiable risk factors present in men and women

\begin{tabular}{|c|c|c|c|c|c|c|}
\hline \multirow[t]{3}{*}{ Risk factors } & \multicolumn{3}{|c|}{ Men } & \multicolumn{3}{|c|}{ Women } \\
\hline & $\begin{array}{c}\text { With } \\
\text { prediabetes }\end{array}$ & $\begin{array}{l}\text { Without glucose } \\
\text { metabolism disorders }\end{array}$ & $p$-value & $\begin{array}{l}\text { With } \\
\text { prediabetes }\end{array}$ & $\begin{array}{l}\text { Without glucose } \\
\text { metabolism disorders }\end{array}$ & $p$-value \\
\hline & $\mathrm{N}=595$ & $N=388$ & & $\mathrm{~N}=589$ & $N=450$ & \\
\hline \multicolumn{7}{|l|}{ Smoking habit } \\
\hline Current smoker & 18.7 & 24.7 & 0.003 & 14.6 & 20.2 & 0.580 \\
\hline \multicolumn{7}{|l|}{ Alcohol consumption } \\
\hline Risky drinker & 34.1 & 31.2 & 0.015 & 12.7 & 12.9 & 0.469 \\
\hline \multicolumn{7}{|l|}{ Physical activity } \\
\hline WHO recommendations not followed & 38.4 & 37.4 & 0.788 & 51.2 & 49.6 & 0.617 \\
\hline \multicolumn{7}{|l|}{ Diet } \\
\hline Incomplete or absent breakfast & 16.3 & 15.7 & 0.859 & 10.9 & 8.0 & 0.137 \\
\hline Non-daily fruit consumption & 26.6 & 25.8 & 0.824 & 17.7 & 20.0 & 0.377 \\
\hline Non-daily vegetable consumption & 49.6 & 52.1 & 0.473 & 36.7 & 37.1 & 0.897 \\
\hline Fish consumed $<3$ times per week & 57.6 & 61.1 & 0.289 & 52.8 & 54.9 & 0.530 \\
\hline Legumes consumed $<3$ times per week & 64.4 & 68.0 & 0.243 & 69.1 & 70.2 & 0.734 \\
\hline \multicolumn{7}{|l|}{ Blood pressure } \\
\hline Hypertension ${ }^{*}$ & 72.3 & 51.3 & $<0.001$ & 61.6 & 44.2 & $<0.001$ \\
\hline \multicolumn{7}{|l|}{ Lipids } \\
\hline Hypercholesterolemia $^{\dagger}$ & 11.3 & 12.9 & 0.481 & 16.6 & 14.7 & 0.440 \\
\hline Hypertriglyceridemia $^{\ddagger}$ & 14.6 & 10.4 & 0.064 & 10.9 & 6.2 & 0.011 \\
\hline Low HDL-Cholesterol $^{\S}$ & 20.4 & 12.2 & 0.001 & 28.3 & 18.9 & 0.001 \\
\hline \multicolumn{7}{|l|}{ Obesity } \\
\hline General obesity" & 42.4 & 23.2 & $<0.001$ & 43.6 & 25.1 & $<0.001$ \\
\hline Abdominal obesity" & 59.4 & 33.0 & $<0.001$ & 75.2 & 52.2 & $<0.001$ \\
\hline
\end{tabular}

Data are showed in percentages.

*Hypertension: mean systolic pressure $\geq 140 \mathrm{mmHg}$, or mean diastolic pressure $\geq 90 \mathrm{mmHg}$, or being under treatment with antihypertensive drugs, or a personal history of arterial hypertension.

${ }^{\dagger}$ Hypercholesterolemia: plasma total cholesterol $\geq 250 \mathrm{mg} / \mathrm{dl}$.

${ }^{\ddagger}$ Hypertriglyceridemia: plasma triglycerides $\geq 200 \mathrm{mg} / \mathrm{dl}$.

s Low HDL-Cholesterol: plasma High-Density Lipoprotein cholesterol $<40 \mathrm{mg} / \mathrm{dl}$ in men, and $<50 \mathrm{mg} / \mathrm{dl}$ in women.

"General obesity: Body Mass Index $\geq 30 \mathrm{~kg} / \mathrm{m}^{2}$.

"Abdominal obesity: waist circumference $\geq 102 \mathrm{~cm}$ in men, and $\geq 88 \mathrm{~cm}$ in women.

pressure, although the mechanisms are not yet fully known [25]. Also, Bardenheier et al. found in their model that the direct effect of hypertension on prediabetes was confounded by waist circumference [22].

A number of studies have reported that alcohol consumption in men, and excessive consumption in particular, is associated with the appearance of prediabetes and type 2 diabetes, whereas alcohol consumption in women displays a protective effect for the appearance of these health problems $[26,27]$. In our study, alcohol consumption was found as a modifiable risk factor for prediabetes in men. Likewise, a lower frequency of risky drinkers was observed among women with prediabetes than among those without glucose disorders, but the differences were not significant.

It has noted that frequency and quality of breakfast is related with regulation of appetite and control of plasma glucose levels [28]. Also, positive associations between skipping breakfast and fasting glucose and fasting insulin have been observed [29]. In our study, although the magnitude of this association was high in women, no statistically significant relationship was found between absent or incomplete breakfast and prediabetes. On the other hand, no relationship was found between consumption of other foods and the presence of prediabetes. This is consistent with the observed by others in relation to fruit and vegetables consumption [14], but it is contrary to the protective effect of foods such as fish, vegetables and legumes on glucose disorders that has been reported [30].

Although the physical exercise is known as a protective factor for the development of type 2 diabetes [31], the failure to follow the WHO physical-activity recommendations was not shown to be associated with the presence of prediabetes in our study. Other studies have obtained 
Table 3 Association between modifiable risk factors and presence of prediabetes in men

\begin{tabular}{|c|c|c|c|c|}
\hline \multirow[t]{2}{*}{ Risk factors } & \multicolumn{2}{|c|}{ Model 1} & \multicolumn{2}{|c|}{ Model 2} \\
\hline & OR & $(95 \% \mathrm{Cl})$ & OR & $(95 \% \mathrm{Cl})$ \\
\hline \multicolumn{5}{|l|}{ Smoking habit } \\
\hline Current smoker vs. never smoker & 0.94 & $(0.65-1.37)$ & 0.77 & $(0.51-1.16)$ \\
\hline \multicolumn{5}{|l|}{ Consumption of alcohol } \\
\hline Risky drinker vs. abstinent & 1.58 & $(1.09-2.28)$ & 1.49 & $(1.00-2.24)$ \\
\hline \multicolumn{5}{|l|}{ Physical activity } \\
\hline WHO recommendations not followed vs. followed & 1.13 & $(0.86-1.48)$ & 1.10 & $(0.82-1.49)$ \\
\hline \multicolumn{5}{|l|}{ Breakfast } \\
\hline Incomplete or absent vs. complete & 1.12 & $(0.78-1.60)$ & 1.10 & $(0.75-1.63)$ \\
\hline \multicolumn{5}{|l|}{ Consumption of fruit } \\
\hline Non-daily vs. daily consumption & 1.16 & $(0.86-1.57)$ & 1.26 & $(0.89-1.77)$ \\
\hline \multicolumn{5}{|l|}{ Consumption of vegetables } \\
\hline Non-daily vs. daily consumption & 0.96 & $(0.74-1.25)$ & 0.88 & $(0.65-1.19)$ \\
\hline \multicolumn{5}{|l|}{ Consumption of fish } \\
\hline Consumption of $<3$ vs. $>3$ times per week & 0.88 & $(0.67-1.16)$ & 0.91 & $(0.68-1.23)$ \\
\hline \multicolumn{5}{|l|}{ Consumption of legumes } \\
\hline Consumption of $<3$ vs. $>3$ times per week & 0.87 & $(0.66-1.14)$ & 0.84 & $(0.63-1.13)$ \\
\hline \multicolumn{5}{|l|}{ Blood pressure } \\
\hline Hypertension ${ }^{*}$ vs. no hypertension & 2.33 & $(1.76-3.08)$ & 1.86 & $(1.39-2.51)$ \\
\hline \multicolumn{5}{|l|}{ Lipids } \\
\hline Hypercholesterolemia $^{\dagger}$ vs. no hypercholesterolemia & 0.85 & $(0.57-1.27)$ & 0.99 & $(0.64-1.53)$ \\
\hline Hypertriglyceridemia ${ }^{\ddagger}$ vs. no hypertriglyceridemia & 1.61 & $(1.07-2.42)$ & 1.19 & $(0.75-1.90)$ \\
\hline Low HDL-Cholesterol ${ }^{\S}$ vs. high HDL-Cholesterol & 1.94 & $(1.34-2.82)$ & 1.88 & $(1.23-2.88)$ \\
\hline \multicolumn{5}{|l|}{ Obesity } \\
\hline General obesity" vs. no general obesity & 2.51 & $(1.88-3.36)$ & 1.43 & $(0.99-2.06)$ \\
\hline Abdominal obesity" vs. no abdominal obesity & 2.87 & $(2.19-3.77)$ & 1.98 & $(1.41-2.79)$ \\
\hline
\end{tabular}

Data are showed in odds ratios (OR) and $95 \%$ confidence intervals $(95 \% \mathrm{Cl})$. Model 1 is adjusted for age, educational level, marital status, region of residence, and family history of diabetes. Model 2 is adjusted for all the variables in the table plus age, educational level, marital status, region of residence, and family history of diabetes. Data in bold indicate statistically significant associations.

*Hypertension: mean systolic pressure $\geq 140 \mathrm{mmHg}$, or mean diastolic pressure $\geq 90 \mathrm{mmHg}$, or being under treatment with antihypertensive drugs, or a personal history of arterial hypertension.

${ }^{\dagger}$ Hypercholesterolemia: plasma total cholesterol $\geq 250 \mathrm{mg} / \mathrm{dl}$.

${ }^{\ddagger}$ Hypertriglyceridemia: plasma triglycerides $\geq 200 \mathrm{mg} / \mathrm{dl}$.

5Low HDL-Cholesterol: plasma High-Density Lipoprotein cholesterol $<40 \mathrm{mg} / \mathrm{dl}$.

"General obesity: Body Mass Index $\geq 30 \mathrm{~kg} / \mathrm{m}^{2}$.

"Abdominal obesity: waist circumference $\geq 102 \mathrm{~cm}$.

similar findings [14]. In relation to smoking, it is a known risk factor of diabetes [32]; however, there is inconsistent evidence about prediabetes. Some findings are agreed with ours [14], but in others smoking was reported as a risk factor [33]. The criteria of prediabetes used in above studies differ from those we used in our study, and therefore, the groups formed in each study are not fully comparable to each other.

\section{Strengths and limitations}

The main strength of the present study is the focus on the prediabetes state. Also, we have included a large number of participants from across Spain from primary care setting. However, when it comes to interpreting the findings, some limitations must be borne in mind. First, this study should be consider as a cross-sectional in design, since it was based on data collected during the baseline stage of a follow-up study. Hence, one cannot exclude the possibility that subjects with prediabetes might have modified their lifestyles and acquired healthier habits. Second, this study included subjects with prediabetes based on HbA1c and FPG criteria, the exclusion of oral glucose overload as criteria for prediabetes was due to it is an expensive and impractical procedure at a primary health- 
Table 4 Association between modifiable risk factors and presence of prediabetes in women

\begin{tabular}{|c|c|c|c|c|}
\hline \multirow[t]{2}{*}{ Risk factors } & \multicolumn{2}{|c|}{ Model 1} & \multicolumn{2}{|c|}{ Model 2} \\
\hline & OR & $(95 \% \mathrm{Cl})$ & OR & $(95 \% \mathrm{Cl})$ \\
\hline \multicolumn{5}{|l|}{ Smoking habit } \\
\hline Current smoker vs. never smoker & 0.82 & $(0.57-1.17)$ & 0.75 & $(0.50-1.11)$ \\
\hline \multicolumn{5}{|l|}{ Consumption of alcohol } \\
\hline Risky drinker vs. abstinent & 1.00 & $(0.66-1.50)$ & 1.13 & $(0.72-1.76)$ \\
\hline \multicolumn{5}{|l|}{ Physical activity } \\
\hline WHO recommendations not followed vs. followed & 1.15 & $(0.89-1.48)$ & 1.04 & $(0.79-1.37)$ \\
\hline \multicolumn{5}{|l|}{ Breakfast } \\
\hline Incomplete or absent vs. complete & 1.48 & $(0.95-2.30)$ & 1.43 & $(0.89-2.30)$ \\
\hline \multicolumn{5}{|l|}{ Consumption of fruit } \\
\hline Non-daily vs. daily consumption & 1.06 & $(0.76-1.48)$ & 0.94 & $(0.65-1.37)$ \\
\hline \multicolumn{5}{|l|}{ Consumption of vegetables } \\
\hline Non-daily vs. daily consumption & 0.98 & $(0.75-1.27)$ & 0.93 & $(0.70-1.24)$ \\
\hline \multicolumn{5}{|l|}{ Consumption of fish } \\
\hline Consumption of $<3$ vs. $>3$ times per week & 0.95 & $(0.73-1.23)$ & 0.94 & $(0.71-1.26)$ \\
\hline \multicolumn{5}{|l|}{ Consumption of legumes } \\
\hline Consumption of $<3$ vs. $>3$ times per week & 0.94 & $(0.71-1.23)$ & 0.88 & $(0.66-1.19)$ \\
\hline \multicolumn{5}{|l|}{ Blood pressure } \\
\hline Hypertension ${ }^{*}$ vs. no hypertension & 1.79 & $(1.37-2.35)$ & 1.44 & $(1.07-1.92)$ \\
\hline \multicolumn{5}{|l|}{ Lipids } \\
\hline Hypercholesterolemia $^{\dagger}$ vs. no hypercholesterolemia & 1.04 & $(0.74-1.48)$ & 1.13 & $(0.78-1.65)$ \\
\hline Hypertriglyceridemia ${ }^{\ddagger}$ vs. no hypertriglyceridemia & 1.58 & $(0.98-2.54)$ & 1.08 & $(0.64-1.80)$ \\
\hline Low HDL-Cholesterol ${ }^{\S}$ vs. high HDL-Cholesterol & 1.82 & $(1.33-2.49)$ & 1.58 & $(1.12-2.23)$ \\
\hline \multicolumn{5}{|l|}{ Obesity } \\
\hline General obesity" vs. no general obesity & 2.26 & $(1.71-2.99)$ & 1.42 & $(1.01-1.98)$ \\
\hline Abdominal obesity" vs. no abdominal obesity & 2.55 & $(1.94-3.35)$ & 1.89 & $(1.36-2.62)$ \\
\hline
\end{tabular}

Data are showed in odds ratios (OR) and $95 \%$ confidence intervals ( $95 \% \mathrm{Cl}$ ). Model 1 is adjusted for age, educational level, marital status, region of residence, and family history of diabetes. Model 2 is adjusted for all the variables in the table plus age, educational level, marital status, region of residence, and family history of diabetes. Data in bold indicate statistically significant associations.

*Hypertension: mean systolic pressure $\geq 140 \mathrm{mmHg}$, or mean diastolic pressure $\geq 90 \mathrm{mmHg}$, or being under treatment with antihypertensive drugs, or a personal history of arterial hypertension.

${ }^{\dagger}$ Hypercholesterolemia: plasma total cholesterol $\geq 250 \mathrm{mg} / \mathrm{dl}$.

${ }^{\ddagger}$ Hypertriglyceridemia: plasma triglycerides $\geq 200 \mathrm{mg} / \mathrm{dl}$.

§Low HDL-Cholesterol: plasma High-Density Lipoprotein cholesterol $<50$ mg/dl.

"General obesity: Body Mass Index $\geq 30 \mathrm{~kg} / \mathrm{m}^{2}$.

"Abdominal obesity: waist circumference $\geq 88 \mathrm{~cm}$.

care level. The two criteria used (FPG and HbA1c) have been widely accepted by the American Diabetes Association [8]. Third, the number of patients included in the prediabetes cohort is greater than the number of patients included in the cohort of subjects without glucose metabolism disorders. Many physicians included patients with normal FPG levels in the second cohort without waiting for the result of the HbA1c analytical tests, when the HbA1c results arrived, some patients were found to be prediabetic and were changed to the prediabetes cohort. Fourth, in our study subjects were health service users, this mean that it would be expected that subjects without glucose metabolism disorders display a higher frequency of risk factors than would the general population; thus, the possibility of identifying risk factors associated with prediabetes would be correspondingly lower than in population-based studies.

\section{Conclusions}

This study provides useful information when considering early detection of individuals with high risk of development diabetes and cardiovascular diseases. The detection of prediabetes in an individual should be accompanied by interventions addressing modifiable risk factors. Obesity, hypertension and low HDL-cholesterol levels have been the modifiable risk factors independently 
related to the presence of prediabetes identified in this study; also, alcohol consumption in men. The magnitudes of the associations were stronger for men than women. Abdominal obesity in both men and women displayed the strongest association with prediabetes.

The available evidence is still scarce, further studies are needed to check these findings and to confirm possible explanations. The existence of differences between men and women underscore the need to analyze data separately by sex, in order to implement specific recommendations to primary prevention of diabetes and cardiovascular diseases in adult population. Finally, these results might influence the primary care practice where, for example, in men, the alcohol consumption should be considered as an additional risk factor of prediabetes compared to women.

\section{Competing interests}

The authors declare that they have no competing interests. Funding was obtained from Sanofi and Novartis to support the development of the data collection platform, the meetings of researchers, and the monitoring of the information collected at baseline. Sanofi and Novartis had no role in the study design, analysis, interpretation of data, writing the manuscript, nor the decision to submit the manuscript for publication.

\section{Authors' contributions}

A D-R was the primary responsible for the statistical data analysis and draft the manuscript. CG-G participated in analysis and interpretation of data, and helped to draft the manuscript. JG-S, and RS contributed to conception and design of the study, acquisition of data, and helped to draft discussion section. LC, SA, JD, PE, JMM, MS, FJS, and JM-C participated in acquisition of data as regional coordinators, and review the initial manuscript. JF contributed to design the study, acquisition of data, and reviewed the initial manuscript. AG and PM contributed to design the study, research of data, and reviewed the initial manuscript. ER conceived and designed the study, and supervised the project, the statistical analysis, and the manuscript writing. All authors read and approved the final manuscript.

\section{Acknowledgements}

We thank the financial support from Sanofi and Novartis.

*The other members of the PREDAPS Study Group are:

M. Alonso (La Eria Health Centre, Asturias), B. Álvarez (Andrés Mellado Health Centre, Madrid), F. Álvarez (La Calzada 2 Health Centre, Asturias), J C. Álvarez (Eras de Renueva Health Centre, León), J. J. Antón (Murcia Centro Health Centre, Murcia), O. Armengol (Poblenou Primary Care Team, Barcelona), L. Ávila (Almachar Ambulatory Care Facility, Málaga), C. Babace (Rodríguez Paterna Health Centre, La Rioja), L. Barutell (Andrés Mellado Health Centre, Madrid), M. J. Bedoya (Hereza Health Centre, Madrid), B. Benito (Raval Sud Primary Care Team, Barcelona), B. Bilbeny (Raval Sud Primary Care Team, Barcelona), M. Birules (Poblenou Primary Care Team, Barcelona), C. Blanco (Sada Health Centre, Coruña), M.I. Bobé (La Mina Primary Care Team, Barcelona), C. Boente (Porriño Health Centre, Pontevedra), A. Borras (Canal Salat Health Centre, Islas Baleares), R. Bosch (Girona 2 Primary Care Team, Girona), M.J. Brito (La Matanza de Acentejo Health Centre, Santa Cruz de Tenerife), P. Buil (Azpilagaña Primary Care Team, Navarra), J.J. Cabré (Reus-1 Primary Care Team, Tarragona), F. Carbonell (Mislata Health Centre, Valencia), F. Carramiñana (San Roque de Badajoz Health Centre, Badajoz), A. Casorrán (Fuente de San Luis Health Centre, Valencia), R. Colas (Santoña Health Centre, Cantabria), B. Cordero (Sta. María de Benquerencia Health Centre, Toledo), X. Cos (Sant Martí de Provençals Primary Care Team, Barcelona), G. Cuatrecasas (Sarrià Primary Care Centre, Barcelona), C. De Castro (Sta. María de Benquerencia Health Centre, Toledo), M. De la Flor (Ntra. Sra. de Gracia Health Centre, Sevilla), C. De la Sen (San Gabriel Ambulatory Care Facility, Alicante), R.M. De Miguel (Pubillas Casas Primary Care Team, Barcelona), A.M. De Santiago (Family \& Community Medicine Teaching Unit, Guadalajara), M. Del Castillo (Andrés Mellado Health Centre, Madrid), D. Domínguez (General Fanjul Health Centre, Madrid), C. Durán (Lavadores Health Centre, Pontevedra), M. Ferreiro (Huerta del Rey Health Centre,
Sevilla), J. Gamarra (Medina del Campo Rural Health Centre, Valladolid), F. García (Don Benito Este Health Centre, Badajoz), L. García-Giralda (Murcia-Centro Health Centre, Murcia), M.T. Gijón (Los Yébenes Health Centre, Madrid), Á. Gómez (Lasarte Health Centre, Guipúzcua), M.C. Gómez (Vélez-Málaga Norte Health Centre, Málaga), J C. González (Girona 3 Primary Care Team, Girona), M. González (Alcantarilla Sangonera Health Centre, Murcia), E. Granero (Vista Alegre Health Centre, Murcia), A.Trinidad Gutiérrez (El Calero Health Centre, Las Palmas), F. Gutiérrez (Bombarda-Monsalud Health Centre, Zaragoza), L. Gutiérrez (Beraun Health Centre, Guipúzcua), M.A.Gutiérrez (Ávila Sur Oeste Health Centre, Ávila), A.M. Hernández (El Calero Health Centre, Las Palmas), M. Ibáñez (Vandel Health Centre, Madrid), R. Iglesias (Laín Entralgo Health Centre, Madrid), D. Igual (Manuel Encinas Health Centre, Cáceres), A. Jurado (Salvador Caballero Health Centre, Granada), R. Llanes (Villanueva de la Cañada Health Centre, Madrid), F. López (Martorell Primary Care Team, Barcelona), R. López (El Carmel Primary Care Team, Barcelona), R. López (Artilleros Health Centre, Madrid), A. Lorenzo (Alcalá de Guadaira Health Centre, Madrid), C. Losada (Adoratrices Clinical Management Unit, Huelva), R. Macía (Roces Montevil Health Centre, Asturias), R. Magallón (Arrabal Health Centre, Zaragoza), F. Malo (Ares Health Centre, Coruña), J. Mancera (Ciudad Jardin Health Centre, Málaga), M.J. Mansilla (Martín de Vargas Health Centre, Madrid), M.T. Marín (General Ricardos Health Centre, Madrid), J.L. Martín (Salvador Caballero Health Centre, Granada), F.J. Martínez (Federica Monseny Health Centre, Madrid), M.C. Martínez (Raval Sud Primary Care Team, Barcelona), R. Martínez (Oñati Health Centre, Guipúzcua), A. Massana (Raval-Sud Primary Care Team, Barcelona), M. Mata (La Mina Primary Care Team, Barcelona), M.S. Mayayo (Martín de Vargas Health Centre, Madrid), J.J. Mediavilla (Burgos Rural Health Centre, Burgos), L. Mendo (Cadreita Health Centre, Navarra), A. Monzón (Vecindario Health Centre, Las Palmas), A.Moreno (San Roque Primary Care Centre, Badajoz), X. Mundet (El Carmel Primary Care Team, Barcelona), T. Mur (Terrassa Sud Primary Care Centre, Barcelona), E. Navarro (Añaza Health Centre, Santa Cruz de Tenerife), J. Navarro (Salvador Pau Health Centre, Valencia), P. Nogales (Las Águilas Health Centre, Madrid), J.C. Obaya (Chopera Health Centre, Madrid), C. Oria (Aizarnazabal-Getaria Health Centre, Guipúzcua), F. Javier Ortega (Campos-Lampreana Health Centre, Zamora), F. Paniagua (Ciudad Jardín Health Centre, Málaga), J.L. Pardo (Orihuela I Health Centre, Alicante), F.C. Pérez (Martín de Vargas Health Centre, Madrid), P.P. Pérez (Mallen Health Centre, Sevilla), N. Piulats (Raval Sud Primary Care Team, Barcelona), R. Plana (Ponteareas Health Centre, Pontevedra), N. Porta (Terrassa Sud Primary Care Centre, Barcelona), S. Poveda (Jumilla Health Centre, Murcia), L. Prieto (Cáceres-La Mejostilla Health Centre, Cáceres), R. Pujol (Tremp Primary Care Team, Lérida), S. Reixa (Arrabal Health Centre, Zaragoza), J. Ripoll (Fuente de San Luis Health Centre, Valencia), A. Rodríguez (Anglès Primary Care Team, Girona), J.J. Rodríguez (Villaviciosa de Odón Health Centre, Madrid), M.A. Rollán (Los Yébenes Health Centre, Madrid), M.T. Rollán (Hereza Health Centre, Madrid), L. Romera (Raval Nord Primary Care Team, Barcelona), P. Roura (Badia del Vallès Primary Care Team, Barcelona), J.F. Rubio (Lasarte Health Centre, Guipúzcua), A. Ruiz (Pinto Health Centre, Madrid), I. Ruiz (La Torrassa Primary Care Team, Barcelona), M. A. Ruiz (Agost Health Centre, Alicante), I. Saenz (Espronceda Health Centre, Madrid), J. Sagredo (Los Rosales Health Centre, Madrid), A. Salanova (Fuente de San Luis Health Centre, Valencia), L.G. Sánchez (Carballeda Health Centre, Zamora), M. Sánchez (Vista Alegre Health Centre, Murcia), G. Sanz (San José Centro Health Centre, Zaragoza), D. Suárez (El Calero Health Centre, Las Palmas), E. Tarragó (Bellvitge Primary Care Team, Barcelona), J. Torrecilla (Bombarda-Monsalud Health Centre, Zaragoza), J.L. Torres (Rodríguez Paterna Health Centre, La Rioja), M. Villaró (Terrassa Sud Primary Care Team, Barcelona).

\section{Author details}

'Department of Preventive Medicine and Public Health, Hospital General Universitario Gregorio Marañón, Madrid, Spain. ${ }^{2}$ Department of Preventive Medicine, Public Health (History of Science), Universidad Complutense de Madrid, Madrid, Spain. ' 2 a Victoria de Acentejo Health Centre, Santa Cruz de Tenerife, Spain. ${ }^{4}$ Martin de Vargas Health Centre, Madrid, Spain. ${ }^{5}$ Porriño Health Centre, Pontevedra, Spain. ${ }^{6}$ Hereza Health Centre, Madrid, Spain. ${ }^{7}$ Raval-Sud Primary Care Team, Barcelona, Spain. ${ }^{8}$ Tafalla Health Centre, Navarra, Spain. ${ }^{9}$ Zumaia Health Centre, Guipúzcua, Spain. ${ }^{10}$ Torrero-La Paz Health Centre, Zaragoza, Spain. ${ }^{11} E s$ Castell Basic Health Unit, Islas Baleares, Spain. ${ }^{12}$ Yecla Health Centre, Murcia, Spain. ${ }^{13}$ Family \& Community Medicine Teaching Unit, Cantabria, Spain. ${ }^{14}$ Endocrinology \& Nutrition Department, Del Mar Hospital, Barcelona, Spain. ${ }^{15}$ Consortium for Biomedical Research in Epidemiology \& Public Health (CIBER en Epidemiología y Salud Pública (IBERESP), Madrid, Spain. 
Received: 27 October 2014 Accepted: 16 December 2014

Published online: 22 January 2015

\section{References}

1. International Diabetes Federation. IDF Diabetes Atlas. 6th ed. Brussels: International Diabetes Federation; 2013.

2. Danaei G, Finucane MM, Lu Y, Singh GM, Cowan MJ, Paciorek CJ, et al. National, regional, and global trends in fasting plasma glucose and diabetes prevalence since 1980: systematic analysis of health examination surveys and epidemiological studies with 370 country-years and 2.7 million participants. Lancet. 2011;378:31-40.

3. Jansson SPO, Andersson DKG, Svärdsudd K. Mortality trends in subjects with and without diabetes during 33 years of follow-up. Diabetes Care. 2010;33:551-6.

4. Wermeling PR, Gorter KJ, van Stel HF, Rutten GE. Both cardiovascular and non-cardiovascular comorbidity are related to health status in well-controlled type 2 diabetes patients: a cross-sectional analysis. Cardiovasc Diabetol. 2012;11:121

5. Harris MI, Klein R, Welborn TA, Knuiman MW. Onset of NIDDM occurs at least 4-7 yr before clinical diagnosis. Diabetes Care. 1992;15:815-9.

6. Medrano MJ, Pastor-Barriuso R, Boix R, del Barrio JL, Damián J, Alvarez R, et al. Coronary disease risk attributable to cardiovascular risk factors in the Spanish population. Rev Esp Cardiol. 2007;60:1250-6.

7. Soriguer F, Goday A, Bosch-Comas A, Bordiú E, Calle-Pascual A, Carmena R, et al. Prevalence of diabetes mellitus and impaired glucose regulation in Spain: The Di@bet.es Study. Diabetologia. 2012;55:88-93.

8. American Diabetes Association. Standards of medical care in diabetes-2011. Diabetes Care. 2011;34 Suppl 1:S11-61.

9. Aroda VR, Ratner R. Approach to the patient with prediabetes. J Clin Endocrinol Metab. 2008:93:3259-65.

10. DeFronzo RA, Abdul-Ghani M. Assessment and treatment of cardiovascular risk in prediabetes: impaired glucose tolerance and impaired fasting glucose. Am J Cardiol. 2011;108:3B-24B.

11. Tuomilehto J, Lindström J, Eriksson JG, Valle TT, Hämäläinen $H$, llanne-Parikka P, et al. Prevention of type 2 diabetes mellitus by changes in lifestyle among subjects with impaired glucose tolerance. N Engl J Med. 2001;344:1343-50.

12. Nathan DM, Davidson MB, DeFronzo RA, Heine RJ, Henry RR, Pratley R, et al. Impaired fasting glucose and impaired glucose tolerance: implications for care. Diabetes Care. 2007;30:753-9.

13. Grundy SM. Pre-diabetes, metabolic syndrome, and cardiovascular risk. J Am Coll Cardiol. 2012:59:635-43.

14. Khambalia A, Phongsavan P, Smith BJ, Keke K, Dan L, Fitzhardinge A, et al. Prevalence and risk factors of diabetes and impaired fasting glucose in Nauru. BMC Public Health. 2011;11:719.

15. Nóvoa FJ, Boronat M, Saavedra P, Díaz-Cremades JM, Varillas VF, La Roche F, et al. Differences in cardiovascular risk factors, insulin resistance, and insulin secretion in individuals with normal glucose tolerance and in subjects with impaired glucose regulation: The Telde Study. Diabetes Care. 2005;28:2388-93.

16. Weyer C, Bogardus C, Pratley RE. Metabolic characteristics of individuals with impaired fasting glucose and/or impaired glucose tolerance. Diabetes. 1999:48:2197-203.

17. Serrano R, García-Soidán FJ, Díaz-Redondo A, Artola S, Franch J, Díez J, et al. Cohort study in primary health care on the evolution of patients with prediabetes (PREDAPS): basis and methodology. Rev Esp Salud Pública. 2013;87:121-35.

18. National Institute on Alcohol Abuse and Alcoholism. Rethinking Drinking: Alcohol and Your Health. Washington D.C: National Institute of Health; 2010.

19. World Health Organization. Global recommendations on physical activity for health. Geneva: World Health Organization; 2010.

20. Martínez-González MA, García-Arellano A, Toledo E, Salas-Salvadó J, Buil-Cosiales P, Corella D, et al. A 14-item Mediterranean diet assessment tool and obesity indexes among high-risk subjects: The PREDIMED trial. PloS One. 2012;7:e43134

21. Salas-Salvadó J, Rubio MA, Barbany M, Moreno B, Grupo Colaborativo de la SEEDO. SEEDO 2007 Consensus for the evaluation of overweight and obesity and the establishment of therapeutic intervention criteria. Med Clin (Barc). 2007;128:184-96.

22. Bardenheier BH, Bullard KM, Caspersen CJ, Cheng YJ, Gregg EW, Geiss LS. A novel use of structural equation models to examine factors associated with prediabetes among adults aged 50 years and older: National
Health and Nutrition Examination Survey 2001-2006. Diabetes Care. 2013;36:2655-62.

23. Zhao X, Zhu X, Zhang H, Zhao W, Li J, Shu Y, et al. Prevalence of diabetes and predictions of its risks using anthropometric measures in southwest rural areas of China. BMC Public Health. 2012;12:821.

24. Heianza Y, Hara S, Arase Y, Saito K, Fujiwara K, Tsuji H, et al. HbA1c 5.7-6.4\% and impaired fasting plasma glucose for diagnosis of prediabetes and risk of progression to diabetes in Japan (TOPICS 3): a longitudinal cohort study. Lancet. 2011;378:147-55.

25. Kang YS. Obesity associated hypertension: new insights into mechanism Electrolyte Blood Press. 2013;11:46-52.

26. Cullmann M, Hilding A, Östenson C-G. Alcohol consumption and risk of pre-diabetes and type 2 diabetes development in a Swedish population. Diabet Med. 2012;29:441-52.

27. Liu C, Yu Z, Li H, Wang J, Sun L, Qi Q, et al. Associations of alcohol consumption with diabetes mellitus and impaired fasting glycemia among middle-aged and elderly Chinese. BMC Public Health. 2010;10:713.

28. Pereira MA, Erickson E, McKee P, Schrankler K, Raatz SK, Lytle LA, et al. Breakfast frequency and quality may affect glycemia and appetite in adults and children. J Nutr. 2011;141:163-8.

29. Smith KJ, Gall SL, McNaughton SA, Blizzard L, Dwyer T, Venn AJ. Skipping breakfast: longitudinal associations with cardiometabolic risk factors in the Childhood Determinants of Adult Health Study. Am J Clin Nutr. 2010;92:1316-25.

30. Feskens EJ, Virtanen SM, Räsänen L, Tuomilehto J, Stengård J, Pekkanen J, et al. Dietary factors determining diabetes and impaired glucose tolerance. A 20-year follow-up of the Finnish and Dutch cohorts of the Seven Countries Study. Diabetes Care. 1995;18:1104-12.

31. Laaksonen DE, Lindström J, Lakka TA, Eriksson JG, Niskanen L, Wikström K, et al. Physical activity in the prevention of type 2 diabetes: The Finnish diabetes prevention study. Diabetes. 2005;54:158-65.

32. Willi C, Bodenmann P, Ghali WA, Faris PD, Cornuz J. Active smoking and the risk of type 2 diabetes: a systematic review and meta-analysis. JAMA. 2007;298:2654-64.

33. Vlassopoulos A, Lean MEJ, Combet E. Influence of smoking and diet on glycated haemoglobin and "pre-diabetes" categorisation: a cross-sectional analysis. BMC Public Health. 2013;13:1013.

\section{Submit your next manuscript to BioMed Central and take full advantage of:}

- Convenient online submission

- Thorough peer review

- No space constraints or color figure charges

- Immediate publication on acceptance

- Inclusion in PubMed, CAS, Scopus and Google Scholar

- Research which is freely available for redistribution 